\title{
Acoustic differences between German and Dutch labiodentals
}

\author{
Silke Hamann
}

Zentrum für Allgemeine Sprachwissenschaft, Berlin, Germany

\author{
Anke Sennema \\ Universität Potsdam, Potsdam, Germany
}

The present article is a follow-up study of the investigation of labiodentals in German and Dutch by Hamann \& Sennema (2005), where we looked at the perception of the Dutch labiodental three-way contrast by German listeners without any knowledge of Dutch and German learners of Dutch. The results of this previous study suggested that the German voiced labiodental fricative / $/$ / is perceptually closer to the Dutch approximant $/ v /$ than to the corresponding Dutch voiced labiodental fricative $/ \mathrm{v} /$. These perceptual indications are attested by the acoustic findings in the present study. German /v/ has a similar harmonicity median and a similar centre of gravity to Dutch / $/$, but differs from Dutch $/ v /$ in these parameters. With respect to the acoustic parameter of duration, German $/ \mathrm{v} /$ lies closer to the Dutch /v/ than to the Dutch / $v /$.

\section{Introduction}

Dutch has three labiodental segments, namely a voiceless fricative /f/, a voiced fricative /v/, and a voiced approximant /v/ (Booij 1995, Gussenhoven 1999). Minimal triplets of the three sounds in word-initial position are given in (1).

$\begin{array}{llll}\text { /f/ } & / \mathrm{v} / & / \mathrm{v} / & \\ \text { fee } & \text { vee } & \text { wee } & \text { 'fairy, cattle, ache' } \\ \text { feil } & \text { vijl } & \text { wijl } & \text { 'error, rasp, while' }\end{array}$

Many speakers of Standard Dutch, apart from those from the Southern part of the Netherlands, neutralize the voiced and voiceless distinction for labiodental fricatives (as for all fricatives) word-initially, see Gussenhoven (1999, p.74).

German learners of Dutch usually have problems acquiring the three-way contrast since their native language differentiates only a voiced and a voiceless 
labiodental fricative [v] and [f] (Kohler 1999, Wiese 1996), see the minimal pairs in (2). ${ }^{1}$

$\begin{array}{lll}\text { /f/ } & / \mathrm{v} / & \\ \text { fein } & \text { Wein } & \text { 'fine, wine' } \\ \text { fort } & \text { Wort } & \text { 'away, word' }\end{array}$

In a perception experiment, Hamann \& Sennema (2005) tested the categorisation of the Dutch labiodental contrast in a closed-set identification task by three groups of listeners, namely Dutch native listeners, German native listeners, and German learners of Dutch. Since the experiment tested not only the categorisation of the labiodentals, the German native listeners had all German consonants as response categories, and the Dutch listeners and the German learners of Dutch had all Dutch consonants as response categories.

Table 1: Mean identification scores (percent correct) of the three test groups in the perception experiment by Hamann \& Sennema (2005), with stimuli in rows, and responses, sorted by language group, in columns. The numbers in each row per language group do not add up to 100 percent, because miscategorisations involving nonlabiodental sounds are not included.

\begin{tabular}{|c|c|c|c|c|c|c|c|c|}
\hline & \multicolumn{2}{|c|}{ German L1 } & \multicolumn{3}{|c|}{ Dutch L2 } & \multicolumn{3}{|c|}{ Dutch L1 } \\
\hline & /f/ & /v/ & /f/ & $/ \mathrm{v} /$ & $/ v /$ & /f/ & /v/ & $/ v /$ \\
\hline$/ \mathrm{f} /$ & $99.5 \%$ & $0 \%$ & $79.0 \%$ & $17.7 \%$ & $2.1 \%$ & $94.8 \%$ & $5.2 \%$ & $0 \%$ \\
\hline$\vec{\Xi} / \mathrm{v} /$ & $16.7 \%$ & $82.8 \%$ & $5.2 \%$ & $74.6 \%$ & $18.5 \%$ & $5.2 \%$ & $94.8 \%$ & $0 \%$ \\
\hline 酷 $/ v /$ & $0 \%$ & $99.5 \%$ & $0.1 \%$ & $6.1 \%$ & $92.6 \%$ & $0 \%$ & $0 \%$ & $99.5 \%$ \\
\hline
\end{tabular}

The results of the experiment (see Table 1) illustrate that the categorization of Dutch $/ \mathrm{f} /-/ \mathrm{v} /-/ \mathrm{v} /$ by German listeners departs from what would have been expected on the basis of the phonemic descriptions of these sounds. German listeners without knowledge of Dutch perceived the Dutch labiodental approximant as their voiced fricative in almost all of the cases, but the Dutch voiced fricative as their voiceless fricative only in 16.7 percent of the cases. Furthermore, German learners of Dutch appeared to have no problems perceiving the Dutch labiodental approximant correctly, even though they do not have such a category in their native language. At the same time, the German L2

1 German has the grapheme $<\mathrm{v}>$, which is used both for $/ \mathrm{v} /$ and for /f/, see e.g. Vase [va:zə] 'vase' and Vieh [fi:] 'cattle', respectively. 
learners had problems perceiving the Dutch labiodental fricative, though they have the same category in their native language. These findings indicate that Germans acquiring Dutch set the Dutch approximant equal to their native voiced fricative.

To account for our findings in Hamann \& Sennema (2005), we proposed that the mismatch in the perception of the Dutch labiodental fricative stems from German /v/ sharing more acoustic properties with the Dutch approximant /v/ than with the corresponding Dutch labiodental /v/. In the following experiment we tested this hypothesis by comparing the acoustic characteristics of the German labiodentals /f, v/ with those of the Dutch labiodentals /f, v, v/.

\section{Experiment}

\subsection{Subjects and material}

Subjects of our experiment were five female speakers of Dutch from Nijmegen, their age ranging from 20 to 34 . For the German stimuli set, five female speakers of German from the Berlin area read the items. They ranged in age from 24 to 47. Speakers either volunteered for the experiment or they were paid for their participation.

The Dutch speakers read the monosyllabic nonsense words /pa, ba, ta, da, $\mathrm{ka}, \mathrm{xa}, \mathrm{fa}, \mathrm{va}, \mathrm{va}, \mathrm{sa}, \mathrm{za}, \mathrm{ca} /$ ten times in randomized order in isolation. The German speakers read the sequences /pa, ba, ta, da, ka, ga, fa, va, sa, za, ça, Ja/ ten times in randomized order in the carrier sentence "Sage ...", 'say ....' . All words were presented orthographically (the Dutch sequence $/ \mathrm{Na} /$ was represented as <sja>, German /sa/ as <ssa> and /ça/ as <cha>). For both languages the whole set of obstruents was included in the reading material because speakers should not be aware of the contrast under investigation.

All speakers were recorded on a DAT recorder with an audio sampling frequency of $48 \mathrm{kHz}$, except for the recordings of two German speakers, which were digitised at a sampling rate of $22.05 \mathrm{kHz}$. Acoustic analyses of the recordings were performed with PRAAT (Boersma \& Weenink 2005), statistical analyses were made with SPSS, version 12 .

\subsection{Acoustic parameters}

The duration of the labiodentals was computed by measuring the point of time of the consonant onset to the beginning of the continuous formants of the

2 One Dutch speaker produced the sequences in the carrier sentence "Hoor je ...”, 'Do you hear ...', and one German speaker produced the sequences without a carrier sentence. 
following vowel. To determine the beginning of the vowel after the Dutch approximant, the rise in amplitude was taken as additional criterion.

To compare the relation of voicing to friction, the degree of acoustic periodicity was determined by calculating the median of the harmonics-to-noise ratio for each labiodental with time steps of $0.01 \mathrm{~s}$, a minimum pitch of $75 \mathrm{~Hz}$, a silence threshold of 0.1 and 1 period per window. This measure is called "harmonicity median" in the following. A harmonicity median of $0 \mathrm{~dB}$ means that there is equal energy in the harmonics and in the noise of a signal, and a harmonicity median of $20 \mathrm{~dB}$ that there is almost $100 \%$ of the energy of the signal in the periodic part (Boersma 1993).

The spectral qualities of the labiodentals were compared by measuring the centre of gravity (see e.g. Jassem 1979 and Gordon, et al. 2002), which is the average of frequencies over the entire frequency domain weighted by the amplitude (with the power spectrum). Signals were high-pass filtered with a centre frequency of $500 \mathrm{~Hz}$ and a smoothing of $100 \mathrm{~Hz}$ to exclude the influence of the fundamental frequency in the voiced fricatives.

\subsection{Results}

Mean values for the parameters consonant duration, harmonicity and gravity centres were computed across languages for subjects and items, and analyses of variance with language as fixed factor and acoustic parameters as dependent variable were carried out on these data. The mean duration (s) of the labiodental consonants are given in Figure 1.

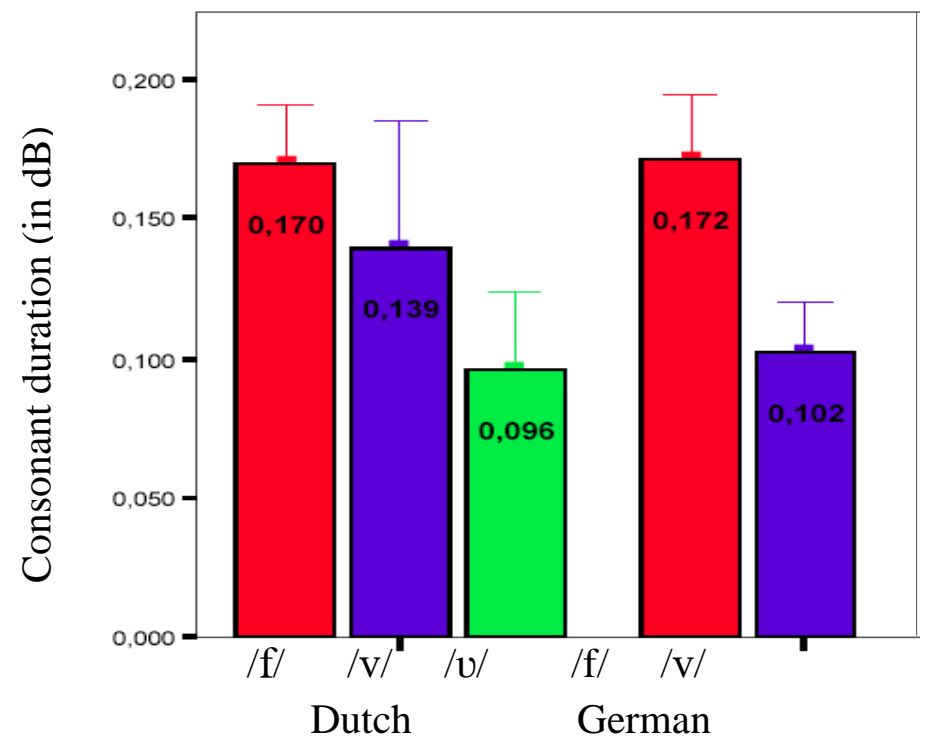

Figure 1: Mean values for consonant duration (s). Error bars indicate standard deviation. 
Results indicate that consonant duration was significantly different for both Dutch $(\mathrm{F}(2,12)=14.24, \mathrm{p}<.001)$ and German $(\mathrm{F}(1,8)=49.81, \mathrm{p}<.0001)$. Bonferroni-adjusted post-hoc tests for the Dutch data revealed significant differences between $/ \mathrm{f} /$ and $/ \mathrm{v} /$, and between $/ \mathrm{v} /$ and $/ \mathrm{v} /$. A two-sided t-test showed no significant difference in duration between Dutch /f/ and German /f/, and between Dutch $/ \mathrm{v} /$ and German $/ \mathrm{v} /$. The difference between Dutch $/ \mathrm{v} /$ and German $/ \mathrm{v} /$ failed to be significant $(\mathrm{t}(8)=-2.175, \mathrm{p}=.061)$.

Average values of the harmonicity median $(\mathrm{dB})$ for the three Dutch sounds and the two German sounds are given in Figure 2.

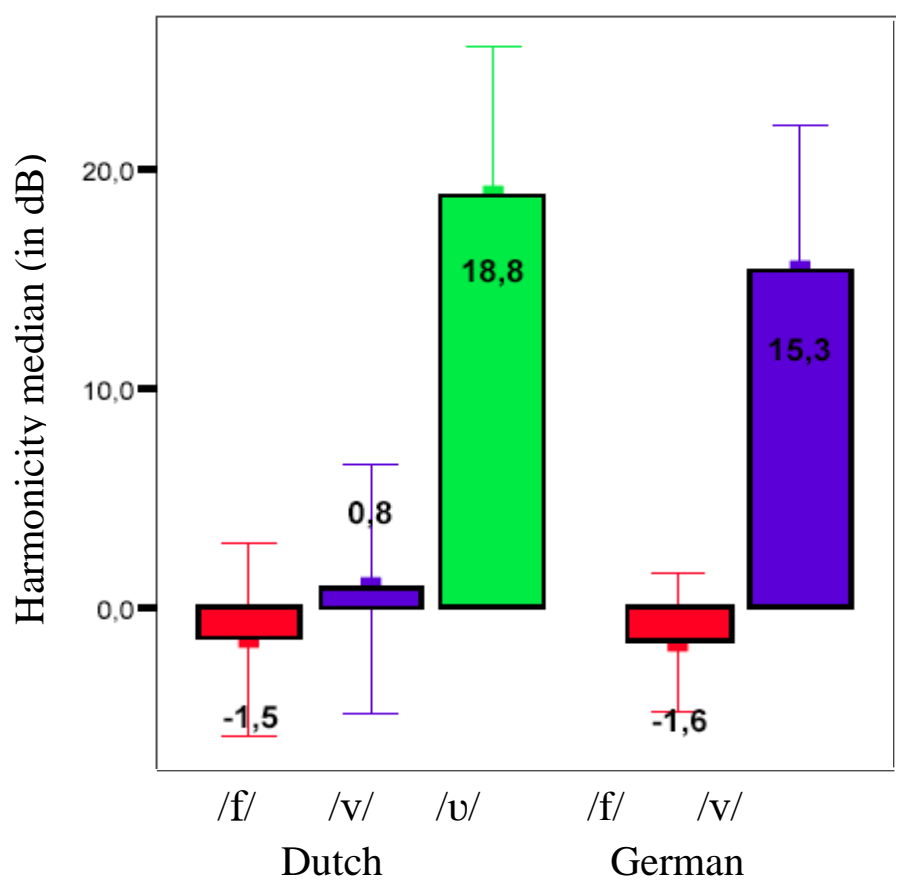

Figure 2: Mean values for the harmonicity median (in $\mathrm{dB})$. Error bars indicate standard deviation.

Analyses of variance showed that harmonicity median within language was significantly different for both Dutch $(\mathrm{F}(2,12)=48.46, \mathrm{p}<.0001)$ and German $(\mathrm{F}(1,8)=27.22, \mathrm{p}<.001)$. Again, Bonferroni-adjusted post-hoc tests for the Dutch data revealed significant differences between /f/ and $/ v /$, and between $/ \mathrm{v} /$ and $/ \mathrm{v} /$. A two-sided t-test $(\mathrm{t}(8)=4.468, \mathrm{p}=.002)$ showed a significant difference in harmonicity median between Dutch $/ \mathrm{v} /$ and German $/ \mathrm{v} /$, yet no significant difference between Dutch / $/ \mathrm{and}$ German /v/ and between Dutch /f/ and German /f/. 
For the comparison of the mean values for the centres of gravity, the two German speakers who were recorded at a lower sampling rate were excluded. This was done because labiodental fricatives show energy in the high frequency domain, which is not taken into account when calculating gravity centres from signals with a low sampling rate.

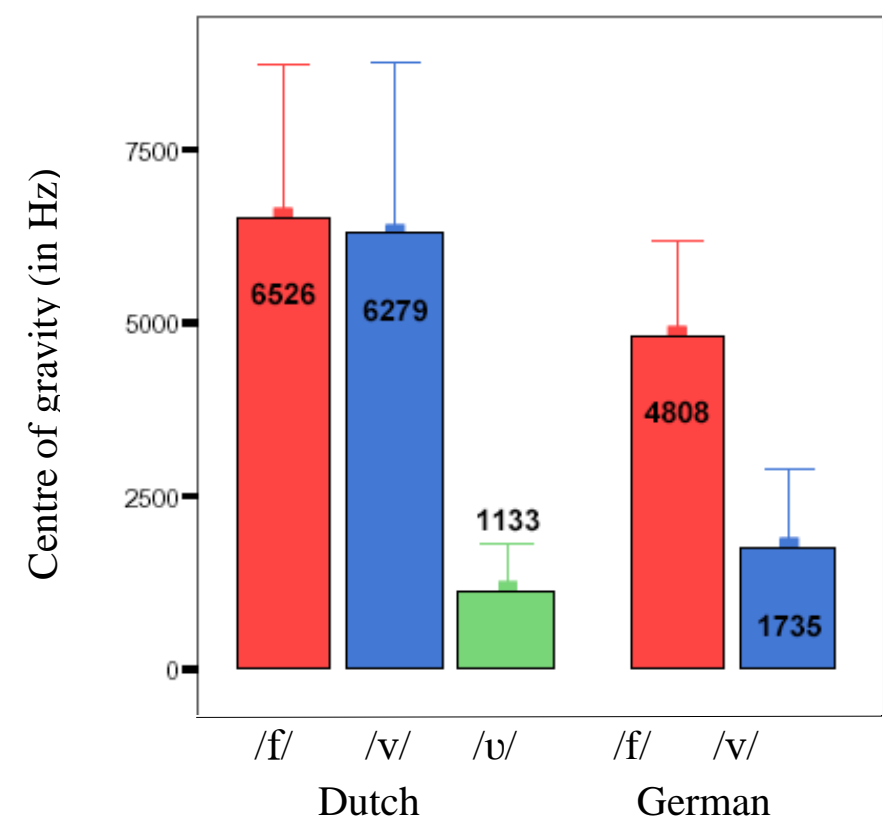

Figure 3: Mean values for centre of gravity (in $\mathrm{Hz}$ ) of the filtered signals. Error bars indicate standard deviation.

Analyses of variance showed that centre of gravity within language was significantly different for both Dutch $(\mathrm{F}(2,12)=15.138, \mathrm{p}<.001)$ and German $(\mathrm{F}(1,4)=23.534, \mathrm{p}<.008)$. Post-hoc tests with Bonferroni-adjustments for the Dutch data revealed significant differences between $/ \mathrm{f} /$ and $/ \mathrm{v} /$ and between $/ \mathrm{v} /$ and $/ \mathrm{v}$. A two-sided t-test $(\mathrm{t}(6)=-3.346, \mathrm{p}=.015)$ showed a significant difference in gravity centre values between Dutch /v/ and German /v/. The difference between Dutch $/ \mathrm{v} /$ and German $/ \mathrm{v} /$ and that between Dutch /f/ and German /f/ were not significant.

\section{Discussion and conclusions}

The results of the present acoustic study show that the German speech sound traditionally described as labiodental fricative and referred to with the IPA symbol $/ \mathrm{v} /$ is, with regard to the parameters tested, acoustically closer to the Dutch labiodental approximant $/ \mathrm{v} /$ than to the corresponding Dutch labiodental fricative /v/. Both German /v/ and Dutch /v/ share a similar harmonicity median 
and a similar centre of gravity. German /v/ is different from Dutch /v/ in these parameters. With respect to the acoustic parameter of duration, German / $/$ / lies in-between the two Dutch sounds $/ \mathrm{v} /$ and $/ \mathrm{v} /$. A summary of these findings is given with the comparison of the three Dutch and the two German labiodentals along three scales in Figure 4.

\begin{tabular}{|c|c|c|c|c|c|c|c|}
\hline \multirow{3}{*}{ Duration: } & \multicolumn{4}{|c|}{ V } & \multicolumn{2}{|c|}{$\mathrm{f}$} & \multirow{2}{*}{$\begin{array}{l}\text { German } \\
\text { Dutch }\end{array}$} \\
\hline & \multicolumn{2}{|c|}{$v$} & \multicolumn{2}{|c|}{$\mathrm{V}$} & & & \\
\hline & & 0 & 120 & 140 & 160 & 18 & (ms) \\
\hline \multirow[t]{3}{*}{ Harmonicity median: } & & $\mathrm{f}$ & & & $\mathrm{V}$ & & German \\
\hline & & & & & & $v$ & Dutch \\
\hline & -5 & 0 & 5 & 10 & 15 & 20 & $(\mathrm{~dB})$ \\
\hline \multirow[t]{3}{*}{ Centre of gravity: } & & V & & $\mathrm{f}$ & \multirow{2}{*}{\multicolumn{2}{|c|}{$\mathrm{vf}$}} & German \\
\hline & $\mathrm{v}$ & & & & & & Dutch \\
\hline & 1 & 2 & 3 & 4 & $\theta$ & & $(\mathrm{kHz})$ \\
\hline
\end{tabular}

Figure 4: Scales comparing the realisations of the two German and the three Dutch labiodentals with respect to the acoustic parameters of duration, harmonicity median, and centre of gravity.

These results can be interpreted as indication that the German voiced labiodental sound is more a glide than a fricative from a phonetical point of view. ${ }^{3}$ In the phonetic literature on German, the voiced labiodental sound is usually described as a fricative (see e.g. Jessen 1998, Kohler 1999, Wängler 1974). However, some notable exceptions exist. Kohler (1995: 154), for instance, mentions that German /v/ can turn into an approximant, especially in initial position. This phrasing implies that the default pronunciation of German / $\mathrm{v} /$ is nevertheless a fricative. A picture more in line with the present findings emerges from Scherer \& Wollmann (1985) who write that German speakers produce little contact for labiodentals, which might cause an approximant-like articulation that does not exist in English (p.93).

3 The present study does not consider phonological arguments in favour of a fricative status of the German voiced labiodental sound. 
The present study thus provides acoustic evidence for the results of Hamann \& Sennema's (2005) perception experiment, where German listeners without knowledge of Dutch classified the Dutch /v/ as their /v/ in almost all of the cases, and German learners of Dutch had problems categorising the Dutch $/ \mathrm{v} /$ correctly. Furthermore, our findings illustrate the problems of equating the phonological categories of two languages that are described as identical but have different phonetic realizations. Due to the limited number of speakers, the present results cannot be more than tentative, and further investigations with more speakers need to confirm the present findings.

\section{Acknowledgements}

We would like to thank Jana Brunner, Christian Geng and Daniel Pape for their careful reading of an earlier version of this article. We gratefully acknowledge funding by the German Science Foundation (DFG) grant GWZ 4/8-1-P2 for Silke Hamann and grant SFB 632-C4 for Anke Sennema.

\section{References}

Boersma, P. (1993). Accurate short-term analysis of the fundamental frequency and the harmonics-to-noise ratio of a sampled sound. Proceedings of the Institute of Phonetic Sciences (University of Amsterdam), 17: 97-110.

Boersma, P. \& Weenink, D. (2005). Praat: doing phonetics by computer (version 4.3.27) [computer programme], Retrieved from http://www.praat.org/.

Booij, G. (1995). The Phonology of Dutch. Oxford: Oxford University Press.

Gordon, M., Barthmaier, P. \& Sands, K. (2002). A cross-linguistic acoustic study of voiceless fricatives. Journal of the International Phonetic Association, 32: 141-174.

Gussenhoven, C. (1999). Illustrations of the IPA: Dutch. Handbook of the International Phonetic Association. Cambridge: Cambridge University Press; 74-77.

Hamann, S. \& Sennema, A. (2005). Voiced labiodental fricatives or glides - all the same to Germans? In: Hazan, V. \& Iverson, P. (eds.) Proceedings of the Conference on Plasticity in Speech Processing. London: UCL; 164-167.

Jassem, W. (1979). Classification of fricative spectra using statistical discriminant functions. In: Lindblom, B. \& Öhman, S. (eds.) Frontiers of Speech Communication Research. New York: Academic Press; 77-91.

Jessen, M. (1998). Phonetics and phonology of tense and lax obstruents in German. Amsterdam: Benjamins.

Kohler, K. (1995). Einführung in die Phonetik des Deutschen. Berlin: Erich Schmidt.

Kohler, K. (1999). Illustrations of the IPA: German. Handbook of the International Phonetic Association. Cambridge: Cambridge University Press; 86-89. 
Acoustic differences between German and Dutch labiodentals

Scherer, G. \& Wollmann, A. (1985). Englische Phonetik und Phonologie. Berlin: Erich Schmidt Verlag.

Wängler, H.-H. (1974). Grundriss einer Phonetik des Deutschen. Marburg: N.G. Elwert Verlag.

Wiese, R. (1996). Phonology of German. Oxford: Oxford University Press. 